\title{
Vaccinating in the age of apathy: measles vaccination in Canada, 1963-1998
}

\author{
n Cite as: CMAJ 2018 April 3;190:E399-401. doi: 10.1503/cmaj.171238
}

CMAJ Podcasts: author interview at https://soundcloud.com/cmajpodcasts/171238-medsoc

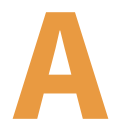

$\mathrm{t}$ an international vaccine symposium held in Toronto on May 17, 1972, US Center for Disease Control Immunization Branch Chief Dr. John Witte commented on the present need "to get more measles vaccine out of the vial and into the child." ${ }^{1}$ Vaccination rates varied from $70 \%$ in Minnesota to $17 \%$ in Pennsylvania, neither of which approached the $95 \%$ required for herd immunity. Canadian statistics were not available until the late 1960s, but outbreaks in the 1970s and 1980s show that herd immunity was also a problem in this country. For Dr. John O. Godden, a CMAJ editor, and other Canadian experts, lack of uptake meant that vaccination was "a battleground where apathy is [a] greater enemy than disease."

How had this situation developed less than a decade after the commercialization of the first measles vaccine in 1963 in a society that apparently had great trust in biomedicine and faith in biomedical technologies? And what lessons does historical analysis of the contested adoption of vaccines for measles have for current concern about vaccine hesitancy $?^{2}$ The history of measles vaccination, long before the Wakefield autism claim in $1998,{ }^{3}$ contextualizes the emergence of active and passive opposition to vaccination and highlights problems with trust that impede effective communication between parents, health care providers and governments.

\section{Parent apathy and anxieties}

The turbulent 1960s contributed to the perception of parental apathy toward vaccination in general among Canadian experts as they witnessed the emergence of new styles of parenting, second-wave feminism and the popularization of alternative medicine. In Quebec, the Quiet Rev-

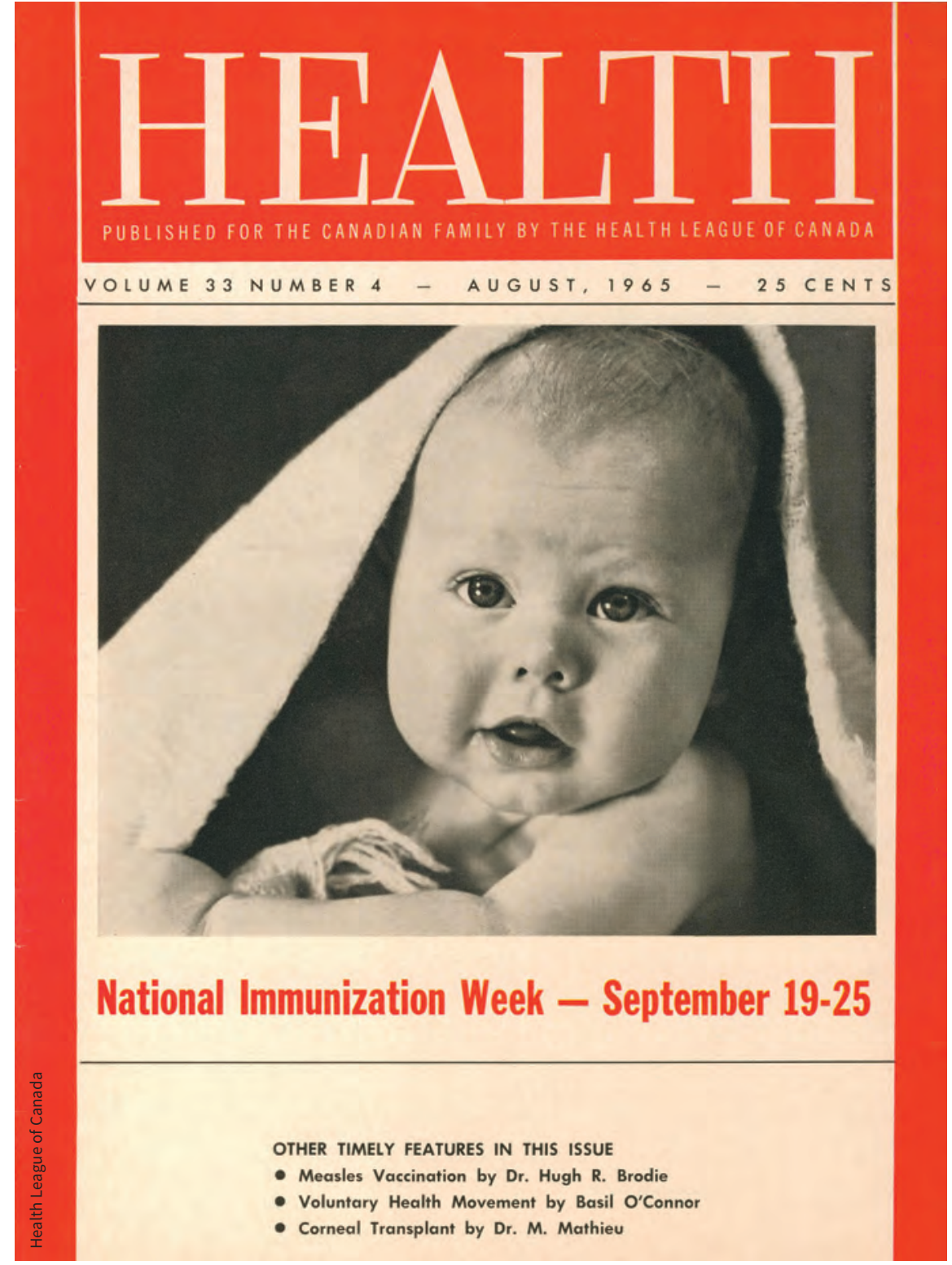

olution, the rise of the nationalist movement and the advent of medicare provided the impetus for Dr. Paul-Émile Chevrefils (a doctor, naturopath and chiropractor) to launch a movement against mandatory smallpox vaccination and for medical freedom. His predictions of the emergence of a "nouveau Québécois," whose good health was based on eating organic food and rejecting pharmaceutical 
products, were widely covered in the media. Health foods and concern about toxic drugs emerged in English Canada too, especially in the wake of the thalidomide scandal of 1962 . Soon, public debates about the mass use of a new, insufficiently tested vaccine for swine flu in $1976,{ }^{4}$ the dangers of fluoridation and the safety and efficacy of vaccines in general contributed to declining parental trust in biomedical technologies.

Claiming that many parents regarded measles as a benign childhood disease, medical experts tried to shift the discussion by citing the dangers of the disease and the cost benefits of its prevention. During the 1970s, as the provinces adapted to medicare, vaccination experts lamented a lack of uptake of the measles vaccine and estimated that $25 \%$ of children in Ontario and 50\% in Quebec had not received their shots in $1975 .{ }^{5}$ Following a series of measles outbreaks, and the apparent success in the United States of a policy requiring vaccination at school entry, ${ }^{6}$ New Brunswick, Ontario and Manitoba passed similar legislation.

In Ontario, the Committee Against Compulsory Vaccination and the Association for Vaccine Damaged Children emerged in response to the legislation. Led by Edda West and other feminists, these groups claimed that doctors and public health nurses misled parents about infant vaccination requirements and called for parental choice. Threatening a charter challenge, the protest groups compelled the Ontario government to amend the Immunization of School Pupils Act to include exemptions in 1984. Legal cases against several Ontario health units, an administering physician and a vaccine manufacturer were settled out of court with little publicity. In Quebec, parents of three children considered to be victims of the vaccines for diphtheria and tetanus toxoids and pertussis, measles and measlesmumps-rubella launched legal battles that resulted in the creation of Canada's only vaccine compensation fund in 1987.

Community-based midwifery groups began to gain acceptance in the 1980s and to challenge medical expertise in childbirth. This was paralleled by new parenting advice that stressed the importance of parental instinct. Before the emergence of attention-deficit/hyperactivity disorder and autism as postvaccination concerns, parents also had more pressing concerns, such as growing levels of allergies and asthma. Thus, by the 1990s, the national and international focus on children, children's rights and child health, allied with new approaches such as attachment parenting, made young parents more willing to question whether their child would benefit from vaccination.

\section{Medical mismanagement}

Doctors were alerted early to the low vaccine uptake. At the 1972 Toronto international vaccine symposium, Dr. William Feldman, a professor of pediatrics at McMaster University, presented results of a survey of physicians in Hamilton, Ontario, about their vaccination practices during a measles outbreak in 1971-72. He had found that $86 \%$ of the 114 children admitted to hospital with complications had never received the measles vaccine. When the surveyed physicians were asked why, $50 \%$ "gave no reason." As Feldman and his colleague, Dr. Bryce Larke - the conference organizer - noted, "increased educational campaigns to counter public and professional apathy" were needed. ${ }^{1}$ And for Larke, this meant including infectious diseases and their prevention in the medical school curriculum. ${ }^{7}$ But the explosion of biomedical knowledge pushed prevention to the fringes of medical training, with the result that a survey of McMaster medical graduates in the early 1980 s found $60.5 \%$ unprepared to provide public health information and $51.8 \%$ unsure of their expertise in preventive care. ${ }^{8}$

The gradual decline in measles cases since the late 1960s may also have contributed to the lack of sustained child vaccination by health care practitioners who increasingly found the disease difficult to diagnose. Administration of the vaccine also varied. A 1977 report by the Ontario Health Council noted that some doctors gave the measles vaccine before 12 months while maternal antibodies were still active, whereas others did not store or dilute the vaccine properly because they did not understand its technical requirements. Many were also confused by the conflicting vaccination schedules proposed by the
Canadian Paediatric Society, the Ontario Ministry of Health and the World Health Organization. ${ }^{5}$ Over time, some of these problems were rectified through the creation of the Canadian Immunization Guide and, starting in 2002, vaccinology training as part of residency programs. But before the 1990s, lack of sustained training in the rapidly changing science of immunology left health care practitioners with limited knowledge to provide guidance when asked to explain the benefits of vaccination to anxious parents.

\section{State apathy}

In 1979, the International Year of the Child, proclaimed by UNESCO (United Nations Educational, Scientific and Cultural Organization) to draw attention to problems that affected children, Feldman published an op-ed in Canadian Family Physician calling on Canada's doctors to educate the public about vaccination. He said, "the goal of universal immunization ... is an achievable goal, but only if politicians see it as such." Pinpointing lack of political will was crucial, as the division of powers between federal and provincial or territorial governments contributed to a "patchwork" of vaccination policies throughout Canada. ${ }^{10}$ The National Advisory Committee on Immunization has provided scientific evaluation of new vaccines before licensing since its inception in 1964, but each province continues to decide whether to adopt the newly approved vaccine and to follow its own vaccination schedule. ${ }^{11} \mathrm{~A}$ steady rise of vaccine prices as not-for-profit Canadian vaccine producers, such as Ontario's Connaught Laboratories and Quebec's Institut Armand-Frappier, were privatized and international producers consolidated into multinational conglomerates exacerbated the lack of national consensus. ${ }^{12}$ From the 1970s to the present, provinces have had to make tough decisions in terms of who gets what and at what cost.

Measles outbreaks in the 1970 s and 1980 s corresponded with a shift to individual rather than collective responsibility for personal health and health promotion, exemplified by the Lalonde report, $A$ New Perspective on the Health of Canadians (1974). ${ }^{13}$ Within hospital-based and cure-oriented health care systems, vaccination now had to be justified in terms of 
its costs and benefits in a political climate focused on evaluation and cost-cutting. A mobile population and steady increase in working mothers saw vaccine availability and affordability become political issues that were difficult to resolve. Advertising and pamphlets provided basic information, but did not constitute an effective response to growing public concern regarding some vaccines.

Even the creation of National Immunization Month in November 1977 by Larke and the Canadian Paediatric Society failed to increase vaccine uptake. Then the appearance of HIV/AIDS, and of a vaccine for hepatitis $B$ that required funding and human resources, distracted political will from efforts to control traditional vaccinepreventable diseases. In 1981, the National Advisory Committee on Immunization and the Canadian Paediatric Society urged the federal government to help provinces eliminate indigenous measles transmission (that is, transmission of existing strains within Canada), but there was little in the way of leadership until the epidemic of more than 10000 cases in Quebec and Ontario in 1989-90 highlighted the challenge of controlling this extremely contagious disease.

Bowing to intensifying pressure from the Pan American Health Organization to eliminate measles in the Americas, the federal government established elimination target dates for measles and rubella and agreed to purchase vaccine for a national "catch-up" campaign, which British Columbia, Quebec and Ontario undertook in 1996-97. Aided by efforts to increase child vaccination in the remaining provinces and territories, Canadian experts were finally able to claim that indigenous measles had been eliminated by 2002 . Subsequent outbreaks in 2007 , 2011, 2014-15, although they might have resulted from imported cases, continue to raise questions about vaccination uptake and vaccination-uptake promotion.

\section{Conclusion}

Experts have pointed to apathy as a key factor in the ongoing battle to eliminate measles transmission through universal vaccination. Apathy has taken many forms in Canada since the 1960s and could be related to what is now labelled as vaccine hesitancy. We have shown that it was not exclusive to parents and that it could be explained, at least in part, by issues of accessibility to efficient vaccines, poor training of health care providers and an enduring lack of political will to implement a single vaccination schedule throughout Canada. The situation was further complicated by the general erosion of social trust in experts and lack of education about and promotion of vaccines. Understanding the past is essential to explaining Canadians' decisions regarding measures to prevent disease and enhance their health.

\section{Heather MacDougall PhD}

Department of History, University of Waterloo, Waterloo, Ont.

\section{Laurence Monnais PhD}

Département d'histoire, Université de Montréal, Montréal, Que.

\section{References}

1. Godden JO. Vaccination - a battleground where apathy is greater enemy than disease. Can Med Assoc J 1972;107:79-82.

2. Dubé E, MacDonald NE. Addressing vaccine hesitancy and refusal in Canada. CMAJ 2016;188:E17-8.

3. Godlee F, Smith J, Marcovitch H. Wakefield's article linking MMR vaccine and autism was fraudulent. BMJ 2011;342:c7452.

4. Neustadt RE, Fineberg HV, editor. The swine flu affair: decision-making on a slippery disease. Washington: National Academies Press; 1978.

5. Immunization. Archives of Ontario, Record Group 163-0-572;9-10. Toronto: Ontario Council of Health; 1977.

6. Colgrove J. State of immunity: the politics of vaccination in twentieth-century America. Berkeley (CA): University of California Press; 2006.

7. Clinical considerations in the control of viral infections [special report]. In: Proceedings of the International Symposium on Vaccines; 1972 May 17; Toronto. Ottawa: Canadian Paediatric Society. Canadian Paediatric Society Archives;29-33.

8. Woodward CA, Ferrier BM. The content of the medical curriculum at McMaster University: graduates' evaluation of their preparation for postgraduate training. Med Educ 1983;17: 54-60.

9. Feldman W. Immunization and the year of the child: an achievable goal. Can Fam Physician 1979;25:256.

10. A patchwork policy: vaccination in Canada. CMAJ 2003;168:533, 535

11. Ismail SJ, Langley JM, Harris TM, et al. Canada's National Advisory Committee on Immunization (NACl): evidence-based decision-making on vaccines and immunization. Vaccine 2010;28(Suppl 1): A58-63.

12. Blume S. Immunization: how vaccines became controversial. London (UK): Reaktion Books Ltd.; 2017.

13. Lalonde M. A new perspective on the health of Canadians: a working document. Ottawa: Public Health Agency of Canada; 1974.

This article has been peer reviewed.

Funding: This work has received the support of the Canadian Institutes of Health Research (grant no. 130394). 